This item was submitted to Loughborough's Research Repository by the author.

Items in Figshare are protected by copyright, with all rights reserved, unless otherwise indicated.

\title{
Gendered identities in self-descriptions of electoral candidates in a French National Sport Federation
}

PLEASE CITE THE PUBLISHED VERSION

http://dx.doi.org/10.1080/16184742.2010.524239

PUBLISHER

Routledge (@ Taylor \& Francis)

VERSION

AM (Accepted Manuscript)

LICENCE

CC BY-NC-ND 4.0

\section{REPOSITORY RECORD}

Ferrand, Claude, lan P.D. Henry, and Alain Ferrand. 2019. "Gendered Identities in Self-descriptions of Electoral Candidates in a French National Sport Federation”. figshare. https://hdl.handle.net/2134/15227. 
This item was submitted to Loughborough's Institutional Repository (https://dspace.lboro.ac.uk/) by the author and is made available under the following Creative Commons Licence conditions.

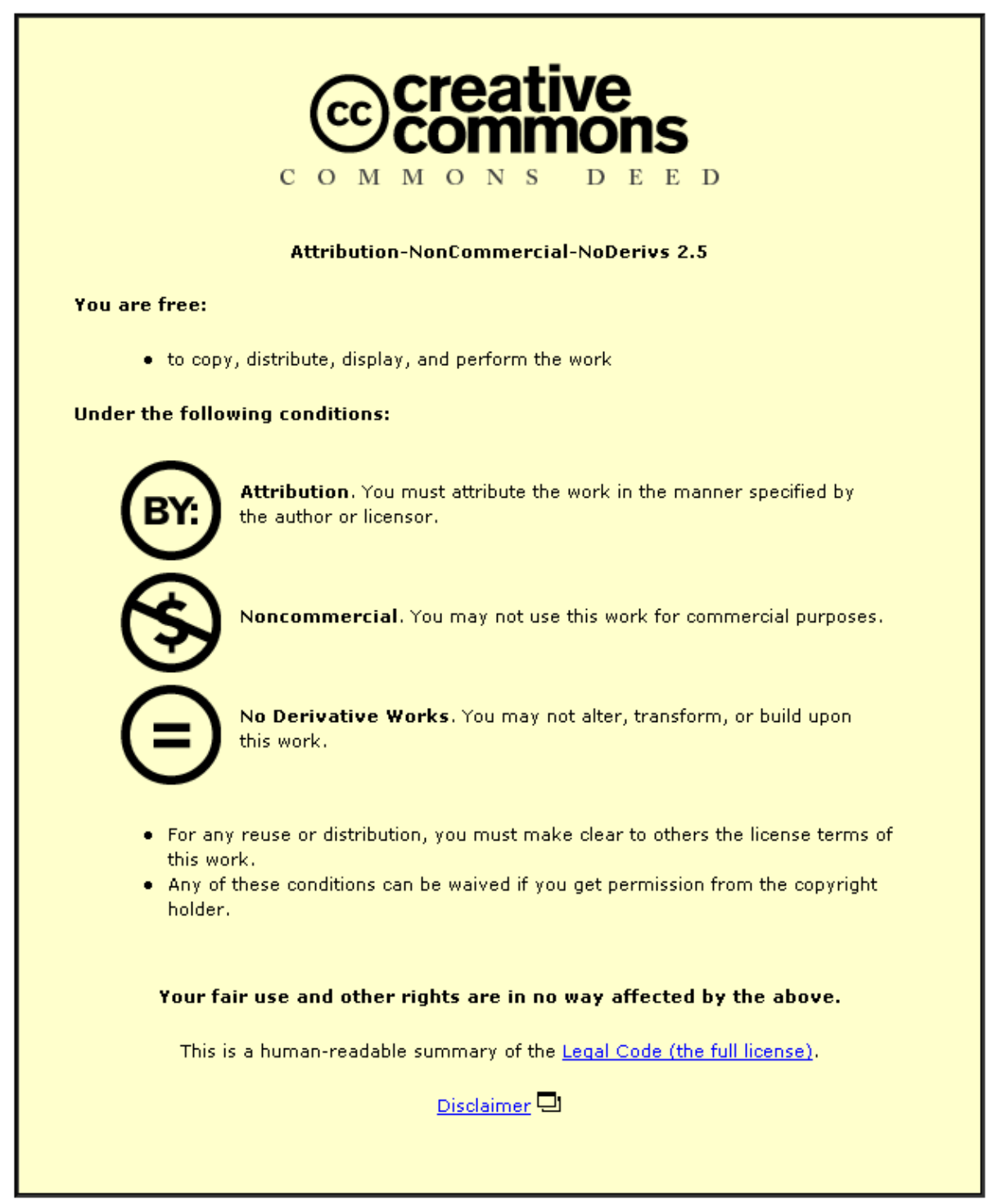

For the full text of this licence, please go to: http://creativecommons.org/licenses/by-nc-nd/2.5/ 
Ferrand, Claude, Henry, lan and Ferrand, Alain(2010) 'Gendered Identities in SelfDescriptions of Electoral Candidates in a French National Sport Federation', European Sport

Management Quarterly, 10: 5, $531-552$

\title{
Gendered Identities in Self-Descriptions of Electoral Candidates in a French National Sport Federation
}

Claude Ferrand ${ }^{\mathrm{a}}$; Ian Henry ${ }^{\mathrm{b}}$; Alain Ferrand ${ }^{\mathrm{c}}$

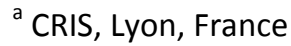

${ }^{\mathrm{b}}$ Centre for Olympic Studies and Research, Loughborough University, Loughborough, UK

${ }^{c}$ Centre De Recherche En Gestion, University of Poitiers, Poitiers, France

\begin{abstract}
The aim of this study was to evaluate ways in which male and female candidates for election to the Executive Committee of a National Sport Federation (NSF) for the period 2004_2008 defined themselves in their candidate self descriptions (CSD). Forty-one statements of candidates were subjected to textual data analysis (using ALCESTE software). Four lexical classes were identified, and the demographic profiles of the authors contrasted. The classes identified were subsequently subjected to correspondence analysis which identified two factors explaining $76.6 \%$ of total variance, reflecting respectively, gendered roles (first factor) and presence/absence of previous national level experience (second factor). Findings provide a discursive perspective on the construction of gendered roles in a sporting organisation.
\end{abstract}

\section{Introduction}

The aim of this study is to evaluate ways in which male and female candidates for election to the executive committee of a French National Sport Federation (NSF) for the period 2004_2008 defined themselves and their aspirations in the candidate self descriptions (CSDs) which were circulated to the electorate. These statements may be partly self description (this is who I am*career to date, competencies and experience etc), and partly personal manifesto (this is what I hope to achieve* personal goals and policies for the NSF). This study investigates these phenomena in a French political context which is particularly amenable to reflections on the gendered nature of recruitment practices. Indeed, the French government, through the process of negotiating financial conventions signed with the NSFs, has advised the NSFs to address the issue of establishing a gender balanced management within their recruitment practices. To this end, agreements on objectives concluded between the French government and the NSFs have incorporated clauses aimed at improving the promotion of women in sport at all levels and in all organisational structures, particularly in executive bodies. Moreover, the Sports Law of July 62000 and the Decree 2004_22 (issued in 2004) specified that the support offered by the French government would only be provided for those NSFs which would guarantee equal opportunities for women and men in their recruitment practices (article 16, appendix 1, paragraph 2.2.2.1). These incentivising legislative procedures aimed at fostering opportunities for female managers were intended to promote diversity, and to address the lack of credibility of sports organisations in relation to the gendered nature of recruitment practices.

Although a considerable amount of research has explored the underrepresentation of women in senior management, relatively less research has focused on candidates for boards of sport organisations such as NSFs (Claringbould \& Knoppers, 2007; Hovden, 2000) and of National Olympic Committees (Henry et al., 2004). Executive boards of NSFs are a fertile site for the study of gender relations because these are places of organisational power, and in essence, they determine the goals of senior management. To address this research purpose, we discuss how a two-stage discourse analysis procedure can contribute to our 
understanding of the gendered nature of selfdescription given by male and female candidates for election in a NSF. First, to contextualise our study we examine the results of earlier studies of French NSFs which have focused on gender. Subsequently we go on to explain how the discourse of candidates has been analysed in two stages. The first stage uses a computer-assisted method of textual analysis (i.e. the ALCESTE, Analyse des Lexe'mes Co-occurentes dans les Enonce's Simples d'un Texte) which identifies patterns of word usage, and clusters together similar speech patterns. The second stage involves an analysis of the clusters of terms used and the demographic features of sub-groups of language users identified in term of purpose and effect. Stage one thus identifies the nature of the discursive structures and the types of speaker with whom they are associated (and thus presents, in effect, a sophisticated form of quantitative content analysis) while stage two represents the analysis of why particular types of speakers engage in the type of discourse they do, and the ends such discourses may consciously or unconsciously achieve. We subsequently analyse how the results of that analysis are related to our own theoretical position. Finally, the article concludes by proposing some suggestions for further research.

\section{Gendering Management and Post-structuralism}

Aitchison (2005, p. 422) indicated that "whereas the 1980s came to be dominated by structuralism-feminism accounts of gender relations across social sciences, including sport studies and management studies, the 1990s gave way to the cultural turn and the increasing influence of post-structural feminist theories". Indeed, a number of studies have begun to emerge in the field of sport and leisure management in more recent years. Some have adopted poststructuralist approaches to analyse sport equity (Aitchison, 2000; Hoeber, 2004; Hovden, 2005; Shaw\&Hoeber, 2003; Shaw\&Penney, 2003), to emphasise the discursive construction of gendered identities by both men and women (Buzzanell \& Liu, 2005; Gatenby \& Hume, 2004), to offer perspectives such as forms of critical feminist theory (Aitchison, 2005; Shaw\&Slack, 2002), an application of discourse ethics (Henry\&Institute of Sport and Leisure Policy, 2007), or an alternative frame of analysis (Shaw \& Frisby, 2006). These authors share a concern, which is perhaps most strongly evident in post-structural analysis, with the contribution which both men and women make to the social construction of gendered relations in management. Consequently, in order to fully examine the way in which gendered subjectivities are constituted, appropriated and challenged, it is interesting to use a poststructuralist approach analysing the CSDs.

Language is central to poststructuralist perspectives, which often employ discourse analysis to read between the lines of social and cultural relations to identify and make sense of the power relations inherent in social and cultural processes. Alvesson and Billing $(1997$, p. 41) argued that, "to the extent that men and women are of interest to study, it is the discourses in which they are constituted that are relevant to explore" with discourses being defined as "a set of statements, beliefs and vocabularies that is historically and socially specific and that tends to produce truth effects-certain beliefs are acted upon as true and therefore become partially true in terms of consequences" (Alvesson \& Billing, 1997, p. 40).

Specifically, with regard to the current study, the two stage discourse analytic approach allows for interrogation of a data set in which men and women make "(re)presentations of self" designed to appeal to the existing electorate of their NSF in the political context of a changed electoral system, so that their discourses offer a certain sort of reality" (Weedon, 1997). Social reality and its patterns of dominance are constructed through established understandings of what can and cannot be said while still seeming sensible or credible (Fletcher, 1998). Moreover, Acker (1990) has indicated that the discourses were gendered. 
By gendered, this author means that the knowledge that informs assumptions and interpretations of managers roles is influenced by discourses concerning "socially produced distinctions between male and female, masculine and feminine" (Acker, 1990, p. 146). Indeed, researching gender in management and organisation theory has largely involved establishing the idea of difference in terms of masculinity and femininity. Shaw and Hoeber (2003) behind the title "A Strong Man is Direct, and a Direct Woman is a Bitch" have underlined that when a man adopts "masculine traits" he is strong and when a woman does the same, she is a "bitch". So, discourses of masculinity, often linked to leadership roles and men, are influential in sport organisations and can serve to undermine discourses of femininity that are frequently associated with subordinate roles and women (Hovden, 2005; Kerfoot \& Knights, 1998; Knights \& Kerfoot, 2004). However, a poststructuralist perspective can develop a new knowledge for understanding gender differences and disrupting the binary opposition of feminine and masculine. It has been argued that men and women are not just socialised into becoming one gender or the other. Gender can be viewed as a fluid and changeable social construct experienced and practised with variations within different cultures. Thus, decomposing the language of the candidates can allow greater attention to a reality as being much more fragmented, diverse, tenuous and culture-specific. It is perhaps ironic that this fluid, inter-subjective construction of identity can be subject to highly structured forms of analysis, but as Reinert (2002) has argued discourse analysis tools, such as the textual data analysis software ALCESTE, are designed to enable us to gain access to the subjects' perception and assessment in a particular situation, and to analyse the structure of their discourses, their cohesion or its absence which reflect underlying structures. The technique for identifying underlying structures of language use of itself does not provide a warrantable account (Wood \& Kroger, 2000), but rather it is the analysis of these structures as a reflection of discursive strategies which constitutes a discourse analysis per se.

\section{Relationships between Discourses of Masculinity and Femininity}

Discourse analysis in a specific social and cultural setting not only describes and illustrates the dominance of discourses of masculinity over discourses of femininity (McNay, 2000). It allows researchers to understand the relationship between the discourses of masculinity and femininity. This relationship has been identified as a possible power relationship because discourses of masculinity are, in general, more valued than discourses of femininity in sport organisations (McKay, 1997). However, women are more than capable of expressing masculinities. McKay, Messner and Sabo (2000) have suggested that women who express discourses of masculinity are perceived by individuals in organisations as people who can adapt to the social hierarchy and access power, meaning their status is not just determined by discourses of femininity, though Shaw and Hoeber (2003) seek to demonstrate how such an approach can marginalise women characterising them as too hard. Moreover, while analyzing the relationship between women and masculinities, discourse analysis can also assist in the examination of men's expressions of discourses of femininities, which may also be complex (Connell, 1995). Thus, post-structuralism focuses on complexity and diversity in thinking about gender (Jones, 1993) and discourse analysis provides a way of working that enables the articulation of contradictions between discourses, creating competing discursive positions.

The issue of the extent to which men and women adopt different leadership and management styles has been debated in the literature for some time (Book, 2000; Fondas, 1997). The existence of gendered roles in leadership and management is viewed as a matter of concern by some feminists who fear that this will legitimate the exclusion of women from 
certain roles. While others argue that the notion of gender difference allows the recognition of the interpersonal qualities associated with female leadership which may contribute to superior performance by women in certain contexts. Empirical analysis of the performance of men and women in leadership roles has tended to suggest that though there may be feminine or masculine tendencies and approaches to leadership and management, both men and women are able to draw on these styles, even though men may be more likely to draw on masculine and women on feminine approaches. Eagly and Johanneson-Schmidt (2001, p. 783) characterise the distinction between gendered approaches to leadership as that between agentic and communal attributes:

\begin{abstract}
Agentic characteristics, which are ascribed more strongly to men than women, describe primarily an assertive, controlling, and confident tendency-for example, aggressive, ambitious, dominant, forceful, independent, daring, self-confident, and competitive. In employment settings, agentic behaviours might include speaking assertively, competing for attention, influencing others, initiating activity directed to assigned tasks, and making problem-focused suggestions. Communal characteristics, which are ascribed more strongly to women than men, describe primarily a concern with the welfare of other people_for example, affectionate, helpful, kind sympathetic, interpersonally sensitive, nurturant, and gentle. In employment settings, communal behaviours might include speaking tentatively, not drawing attention to oneself, accepting others' direction, supporting and soothing others, and contributing to the solution of relational and interpersonal problems.
\end{abstract}

This characterisation is further extended by the distinctions between autocratic and democratic leadership, between task-oriented and interpersonally oriented style, and between transactional and transformational style, with the former in each of these three pairs being ascribed to predominantly masculine and the latter to predominantly feminine behaviours. Yoder (2001, p. 815) also underlines these claims with respect to the gendered nature of transformational and transactional approaches to leadership:

Leadership itself is gendered and is enacted within a gendered context... These contexts exist along a continuum ranging from male-dominated, hierarchical, performanceoriented, power-expressive and thus masculinised contexts (sic) at one extreme to transformational contexts that stress the empowerment of followers at the other pole.

These broadly ideal-typical dichotomous characterisations concerning gendered styles provide a useful backdrop against which to evaluate the nature of the CSDs, and the ways that claims are made by candidates in relation to management and leadership skills produced for the election.

\title{
Gender Issues and French National Sport Federations
}

Research relating to women's access to the executive boards of French NSFs is relatively sparse (Bernadeau-Moreau, 2005; Chantelat, Bayle, \& Ferrand, 2004; Chimot, 2004; Mennesson, 2000, 2004). Thus, Bernadeau-Moreau (2005) and Chimot (2004) have used quantitative analyses and demonstrated that generally French sport organisations are far from being equitable, with fewer women than men in senior positions in sport organisations (e.g. in 2004 , only $6.2 \%$ of French NSF chairpersons were women), and that the dominance of masculinity deeply and historically entrenched in sport organizations was still most present in leading positions. Chantelat, Bayle \& Ferrand. (2004) explored how male and female managers described their managerial positions in the context of an executive committee. They identified a bifurcation which is evident in management literature, with two contrasting types of perspectives. The first suggests that equality implies that women and men are essentially the same and that women gain access to the same levels of professional qualifications, competences in management and decision-making positions as men. By contrast, the second acknowledges the existence of gender differentiation in skills 
and managerial practices. While these two contrasting ideological perspectives (i.e. equality versus difference) have been largely debated in gender research, together with the implications of these understandings for actions for change (Cockburn, 1989; Ozbilgin, 2000; Tinker, 2004), it has been argued that they have not challenged the structural inequalities that are embedded in the organisational culture and processes. Nevertheless, Chantelat et al. (2004) reported feelings of ambiguity among male and female managers and suggested that it would be interesting to take into account how managers construct and deconstruct difference, sameness and identity. Mennesson $(2000,2004)$, by studying the modes of functioning of French female committees in traditionally male sports such as football and boxing, pointed out the necessity of a better understanding of women's access in sport organisations. She described three different kinds of struggles to gain access: (1) women must seek access to existing male-orientated structures; (2) there must be a possibility of creating separate feminine spaces, structures and programs; and (3) dominant, often patriarchal structures must be transformed to suit both male and female needs and expectations. Although the above studies are interesting per se, they do not focus on government policy as an important resource in the discursive construction of gendered nature of recruitment practices. It seems necessary, therefore, to move on and offer new insights for a better understanding of the gendered nature of senior management roles.

Our study focuses on the Gymnastics Federation's Executive Committee, analysing the CSDs for those who submit themselves for election. The French Gymnastics Federation is one of the most female oriented sport organisations in terms of membership in France. In 2005, the Federation had 244,000 club members including 195,200 women and 48,800 men (i.e. $80 \%$ were women). In response to pressures from the government, the executive board members at the end of the 2000_2004 term of office discussed the need to promote a gender balanced management in the executive committee and amended the Federation's internal electoral system, with new rules to be applied for elections in 2004 . The new electoral system was to promote a gender balanced management within the ordinary member, category of the executive committee. It required that in the category ordinary member of the Executive Board, $50 \%$ of those elected had to be women, while for election to positions with a named portfolio (e.g. president, vice-president, treasurer, secretary general) there was to be no requirement in terms of gender. This approach was viewed slightly differently by the male and female members. For the men, implementation of a plan for the feminization of their executive committees was a matter of respect for the law. Fink, Pastore and Riemer (2003) have already underlined organisations that undertook diversity actions as compliance rather than a cultural shift within an organisation. For the women, the issue was somewhat different:

Quotas were against the principle of equal opportunity for all. We simply asked for an equal number of women and men within the category of executive committee ordinary member. This could not be refused to us. The men on the executive committee feared that we might ask for more, given the percentage of women within our Federation (Bontoux, 2005, p. 22).

In this context, it is important that male and female members' distinct standpoints relating to equal opportunity are considered. According to Jaquette (2001) the equality versus difference position is tied to how women view power relations within the organisations. It was thus hypothesized that gender differences between the male and female self descriptions would emerge. Poststructuralists insist that meanings are not fixed in a culture's lexicon but are rather dynamic, always potentially in flux. We predicted that the male and female candidates would suggest different representations of themselves and of what was needed in leading positions in their sport. 


\section{Method}

\section{Participants and Procedure}

Forty one candidates stood for election in the category "ordinary member" to the 2004_2008 executive committee ( 21 men and 20 women) and the mean age of the participants was 52 years. The electoral system is significant in that for the category of ordinary member and equal number of women and men had to be elected. The executive committee had 34 places. Fourteen of these allocated to election of particular categories of member, 1 and a further 20 places allocated to the open category of ordinary member. For these 20 ordinary member places there were 41 candidates. During the general assembly of the Gymnastics Federation, the election was conducted using a plurinominal majority system (in accordance with the policies of the Federation) with two rounds of voting. In this system, during the first round, the delegates are free to vote for any candidate. Those candidates exceeding the required minimum number of votes in the first round are duly elected unless the threshold of 10 members for one gender has been exceeded. In the second round the remaining places are allocated on the basis of the highest vote recorded until the maximum of 10 members has been reached for males or females, with the remaining places being allocated to candidates of the other gender on the basis of the highest number of votes received.

A candidate may only stand for election in the 'ordinary member' category if $s / h e$ supplies a CSD. Thus each candidate wrote a self description of between seven and eighteen lines, which was included with the material distributed to the electors. There were two types of biographical data provided by the candidates: personal data such as name, age, professional status, and role within the public sphere of the sport typically their current office within the Federation's (local, regional or national) structures, and the personal statement. Ethical approval and permission to conduct the study were granted by the French Gymnastics Federation.

\section{Data Analysis}

41 CSDs were incorporated in a document entitled "Candidates for the Election to the 2004_2008 Executive Committee". The structure of the standardised element of the candidature form focused on the formal roles played by the individuals in the Federation. With no required reference to family status or other elements of personal histories, this structure tended to elicit information which emphasised the level of experience (at a senior level) of each of the candidates and, by implication, underplayed the history of dedicated service to the Federation over time at a lower level. Thus, the link between family and professional life/voluntary roles was not evinced by the standardised element of the form. This reflects the argument that family background should not be relevant to one's success or failure in the competitive struggle (De Sensi \& Rosenberg, 1996). The implicit logic is that family status is unimportant since all candidates must display competence, commitment and availability. The time dimension of this logic may be considered as an essential precondition of the Federation in the recruitment of its executive committee, rendering the gendered nature of time in traditional family roles relatively invisible (Leve^que, 2006).

The CSDs were analysed using the ALCESTE software program. The ALCESTE is based on a method originally developed by Benzecri (1981) for analysing linguistic material, which was an extension of the research originally carried out on the mathematical structure of 
language. This method of statistical textual analysis applied to the CSDs focuses on three approaches: lexicometrics, content analysis and data analysis (Lescure, 1999), and involves five main stages as follows. In Stage one, lexicometrics was used to count each word and form, and content analysis was used in a specific form. That is, it helped to cut the text into sequence of sentences, delineating what is called elementary contextual units (ECUs). An $E C U$ is defined as a number of words per unit. The meaning of ECUs is independent from the cutting process. In Stage two, all the words (except auxiliaries) within ECUs were reduced to simple forms. The simple forms were divided into two classes: (1) those which were amenable to analysis (content words) and which were subsequently used to calculate the data matrices and (2) the supplementary forms (i.e. function words such as already, with, always, but ...) which were subsequently used only to help to describe the classes when we reached stage five. Next, in Stages three and four, data analysis was used in order to structure the corpus after it had been reduced to ECUs. The program established a matrix of data which was used to check the presence or absence of each word in each ECU. The ALCESTE created classes of words associated in the same context, with a top-down hierarchical classification program (Benzecri, 1981). The procedure was iterative and maximized a chosen criterion, here chi square (x2, Benzecri, 1981; Reinert, 1990) that was used as a frequency criterion, to identify in the corpus the words significantly repeated, which would then be used to determine the different classes. In Stage five, the procedure used to analyse the classes of extracted ECUs involved two stages. The first stage involved collecting the vocabulary most typical of a given class. This yields a list of the words with the most significant frequency of occurrence (i.e. "those which the candidates tend to use most repeatedly", Noe"I-Jorand, Reinert, Giudicelli, \& Dassa, 1997, p. 185). This list contained two categories of words satisfying x2_3: content words and function words. The second stage involved extracting the ECUs which were the most representative of their class. This provided a key to the meaning of the classes via the actual sentences extracted from the corpus. Thus, each class can be understood as a specific semantic context.

Finally, ALCESTE provides a correspondence analysis along two axes. A spatial, two-dimensional representation of the relations between the classes is generated in which proximity reflects the degree of association. Correspondence analysis aims to account for a maximum amount of association with the first factor, along the first (horizontal) axis. The second (vertical) axis seeks to account for a maximum of the remaining association. SchonhartBailey $(2005$, p. 13) points out that the results are often exploratory in nature: "The resulting analysis provides a framework for the user to formulate his or her interpretation, rather than providing clear-cut conclusions". Consequently, the first and the second authors interpreted the results individually and compare the convergence of their interpretation. This double procedure makes sure that interpretation is not a groundless interpretation. Moreover, peer debriefing sessions including direct meetings with the third author and other researchers considered as "disinterested peers" (Lincoln \& Guba, 1985, p. 308) were conducted in order to debate the authors' interpretations.

\section{Results}

The analysis of the results proceeds in four steps. First, the characteristics of the population being studied are defined. Second, a diagrammatic representation of the top-down hierarchical classification which creates a visualization of the distribution of classes and their lexical contents is discussed. Third, classes are analysed in detail. Finally, the results of correspondence analysis are discussed. 


\section{Main Features of the Population}

Each sheet relating to the details of an individual candidate contained a standardized element which showed the candidate's age, their professional status, and their current role(s) within the different (national, interregional, regional, departmental) structures of the Federation. This standardized element did not require information concerning the candidates' parental and family status. Only four of the candidates (all women) referred in their CSDs to family status as a mother of children (three in one case and four in another), as mother of a high level gymnast, or as assisting her husband in his sporting activities. However, the average age of female candidates ( 48.05 years) suggests that many may be at the stage at which traditional family care roles relating to children may have diminished.

In terms of their involvement in the French Gymnastics Federation at its various levels, some candidates had responsibilities at the departmental level but most were involved in the regional or interregional leagues. Departments are sub-units of regions in France which are the equivalent of counties in the English system of local government. A considerable proportion of candidates (80\%) were in full time employment suggesting that these people would be required to manage their time effectively if they were to undertake additional voluntary work. The assumption of total availability tends to be seen as a self-evident requirement of volunteer senior board members (Acker, 1990; Doherty \& Carron, 2003). The candidates who had previously been elected to the Executive Committee (11 men and 11 women) made reference to their background in the Gymnastics Federation at the national level. Most candidates mentioned their sporting roles. The male candidates performed predominantly administrative functions in the regional leagues rather than technical roles (such as coach, judge, etc.). However for female candidates, the division between administrative and technical roles was more even. Table 1 summarises the main features of the population studied.

\section{Main Features of the Corpora of Discourse}

The total number of occurrences of terms (words or phrase) was 5928 and the total number of separate forms of such terms was 1332 with 767 hapax (terms occurring only once). The average frequency by form was four and the maximum frequency of a form (word or phrase) was 376. The total number of ECUs classified was 161.81 of the $161(50.31 \%)$ were analysed in detail and used to draw up the lexical classes which were most stable. Four classes were identified and composed as follows: Class 1, 22 ECUs, (i.e. 27.16\% of all the ECUs selected); Class 2, 30 ECUs (i.e. $37.04 \%$ of all the ECUs selected); Class 3, 12 ECUs (i.e. $14.81 \%$ of all the ECUs selected), and Class 4, 17 ECUs (i.e. 20.9\% of all the ECUs selected).

The top-down hierarchical classification decomposes the classes until a predetermined number of iterations fail to result in further divisions. The result is an optimised hierarchy of classes, which may be schematised as a dendogram. The top-down hierarchical classification revealed that the strongest contrast in terms of vocabulary is between Class 1 and 2 (see Figure 1), which are also the classes with the largest proportion of males (Class 1 ) and females (Class 3). It also revealed the relative proximity between the Class 1 and 3 and their contrast with the Class 4 and 2. 

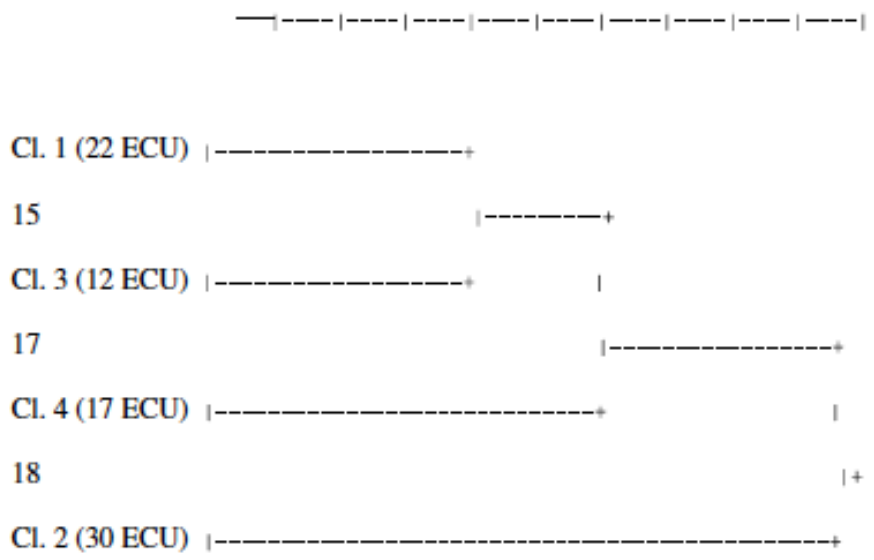

Figure 1. Dendogram indicates the division of the candidate self description statements into stable classes by elementary contextual units using top-down hierarchical classification.

\section{Most Significant Occurrences in Each Class}

Each lexical class contained two categories of significant words, which describe the given class and serve to interpret it: i.e. the content and function words. Class 1 was labelled "positioning of the self in organisational structure of the sport" since the speakers tended to legitimate their candidacy through a discussion of their current position. This class is represented by a significant number of candidates (11) with a majority of them being men (9 of the 11 candidates, $x_{2}$ 6.58) some in retirement x2_11.45) and with the majority holding an administrative office at the regional level. The terms most regularly employed in this discourse focused on locating the authors in their current and previous roles in the Federation structure. Thus, terms such as level (x2_16.10), regional ( $x_{2}$ 13.28), technical (x2_13.11), administration (x2_10.58), and office (x2_10.04) are among the most strongly associated with this lexical class. A lower level of association but still significant is placed on asset (x2_5.11), interest ( $x_{2}$-5.11) and know-how (x2_5.11) (see Table 2). Among the function words, the prepositions in (x2_7.36), always (x2_7.36), if ( $x_{2} 44.87$ ), and but ( $x_{2}$ 3.48) were used suggesting their responsibility in an already stable environment. Of the repeated segments the most representative are I am (x2_10.50) and all (x2_10.27). 
Table 1. Mean feature of the population of candidates whose candidate self-descriptions are being studied

\begin{tabular}{lll}
\hline & Women $(n=20)$ & Men $(n=21)$ \\
\hline Age & mean $=48.05$ & mean $=56.43$ \\
Profession & SD 11.57 & SD 8.83 \\
& 14 civil servants & 10 civil servants \\
& 1 liberal professions & 2 liberal professions \\
& 3 middle management & 9 middle management \\
& 1 student & \\
Regional involvement & 1 no occupation & 2 elected technical roles \\
& 8 elected technical roles & 19 elected admin roles \\
Activity/Retirement & 13 elected admin roles & 15 economically active \\
& 18 economically active & 6 retired \\
\hline
\end{tabular}

Class 2 was labelled "expressing active engagement and commitment" as the CSDs in this lexical class tended to emphasize processual activities and personal commitment. Terms most characteristic of this class include development ( $x_{2}$ 1 15.84), hope ( $x_{2}$ 14.38), involvement (x2_13.03), carry out (x2_13.03), participate (x2_13.03), plan (x2_11.02), pursue (x2_10.95), and passion (x2_9.06). This class is characterised by a slight majority of women (7 of the 12 candidates, (x2_6.98), by economically active individuals ( $\left.x_{2} \_5.65\right)$, by women performing a technical role in their regional leagues ( $x_{2}$ _5.10 and by men and women not previously elected to the executive committee ( $\left.x_{2}{ }_{-} 4.20\right)$. Table 2 illustrates more fully the specific vocabulary of Class 2 which reflects some terms related to participative feminine management used in this case by male and female candidates in self description. The significant function words linked to content words within Class 2 were already (x2_7.15), for (x2_5.23), with (x2_3.47). In addition, among the most frequently repeated segments are some words which evoke an anchorage in the present namely my hope, is, in the present day and my involvement.

Class 3 was labelled as "emphasising experience and competence". This lexical class relates to CSDs by men and women who had been previously elected (x2_5.73). As Table 2 indicates, the specific vocabulary of this class reflects a focus on professional experience and competence. Terms such as know-how (x2_24.19), knowledge (x2_24.11), background (x2_16.60), professional ( $\left.x_{2} \_13.81\right)$, service (x2_4.68) occur in this group. The conjunction words and ( $\left.x_{2}{ }_{-} 4.02\right)$, as ( $\left.x_{2} \_4.77\right)$, in order to ( $\left.x_{2}{ }_{-} 4.13\right)$, and so ( $x_{2}$ _4.77) emphasize the coordination between the propositions made by the candidates.

Class 4 was labelled as the "sport committed recreational actor" reflecting a discourse about initial achievement linked to several years of background in the sport legitimating claims to be a suitable candidate. None of this group had been elected previously to the national Executive, and all except one had performed administrative roles at regional, departmental or club level. Terms such as president ( $x_{2}$ 38.12), commission ( $x_{2}$-7.40), vice president (x2_7.40), judge (x2_19.69), train (x2_15.19), and manage (x2_11.19), relate to roles played but in conjunction principally with department (x2_19.69), (local) association (x2_8.59). The function words most characteristic of this lexical class relate to the concept of time invested in gymnastics: since (x2_5.79), more, (x2_5.14), after ( $x_{2}$ _5.01), then ( $x_{2}$ 2 2.12), during ( $\left.x_{2} \_2.14\right)$. The most frequently repeated segments were I was (x2_15.62), and I have (xz_16.90). 
Table 2. Specific vocabulary of different classes

\begin{tabular}{|c|c|c|c|}
\hline $\begin{array}{l}\text { Class one. } \\
\text { Positioning of the self in } \\
\text { organisational structure of } \\
\text { the sport } \\
\text { - } 11 \text { candidates: } \\
\text { - } 9 \text { men, } 2 \text { women; } \\
\text { - } 8 \text { economically active } \\
\text { and } 3 \text { (men) in } \\
\text { retirement; } \\
\text { - } 11 \text { in administrative } \\
\text { functions in regional } \\
\text { leagues; } \\
\text { - previously elected to } \\
\text { executive committee } \\
\text { (five men) }\end{array}$ & $\begin{array}{l}\text { Class two. } \\
\text { Expressing active engagement } \\
\text { and commitment } \\
\text { - } 12 \text { candidates: } \\
\text { - } 7 \text { women, } 5 \text { men; } \\
\text { - perform technical roles } \\
\text { (5/7 women) and } \\
\text { administrative roles ( } 5 \text { men); } \\
\text { - not previously elected executive } \\
\text { committee ( } 5 \text { women and } 2 \text { men) }\end{array}$ & $\begin{array}{l}\text { Class three. } \\
\text { Emphasising experience } \\
\text { and competence } \\
\text { - } 8 \text { candidates: } \\
\text { - } 6 \text { women and } 2 \text { men; } \\
\text { - administrative roles in } \\
\text { regional leagues ( } 5 \text { women } \\
\text { and } 2 \text { men); } \\
\text { - previously elected executive } \\
\text { committee members } \\
\text { (4 women and one man) }\end{array}$ & $\begin{array}{l}\text { Class four. } \\
\text { The committed recreational } \\
\text { sport actor } \\
\text { - } 8 \text { candidates: } \\
\text { - } 5 \text { women and } 3 \text { men; } \\
\text { - administrative roles in } \\
\text { regional leagues ( } 4 \text { women } \\
\text { and } 3 \text { men); } \\
\text { - not previously elected to } \\
\text { executive committee } \\
\text { (8 candidates) }\end{array}$ \\
\hline $\begin{array}{l}\text { Content word }\left(\chi^{2}\right) \\
\text { level }(16.10) \\
\text { regional }(13.28) \\
13.28 \\
\text { technical }(13.11) \\
\text { administration }(10.58) \\
\text { future }(10.27)\end{array}$ & $\begin{array}{l}\text { Content word }\left(\chi^{2}\right) \\
\text { development }(15.84) \\
\text { hope }(14.38) \\
\text { regional } \\
\text { involvement }(13.03) \\
\text { carry out }(13.03) \\
\text { participate }(13.03)\end{array}$ & $\begin{array}{l}\text { Content word }\left(\chi^{2}\right) \\
\text { know-how }(24.19) \\
\text { knowledge }(24.11) \\
14.38 \\
\text { background }(16.60) \\
\text { listen }(16.60) \\
\text { new (13.81) }\end{array}$ & $\begin{array}{l}\text { Content word }\left(\chi^{2}\right) \\
\text { president }(38.12) \\
\text { departmental }(19.69) \\
\text { hope } \\
\text { judge }(19.69) \\
\text { train }(15.19) \\
\text { function }(11.73)\end{array}$ \\
\hline
\end{tabular}




\section{Correspondence Analysis}

The correspondence analysis identified two factors which explained $76.60 \%$ of the total variance. In Figure 2, the horizontal axis distinguishes the women performing a technical role in their regional leagues at one end of the axis, from men, in retirement, performing an administrative function (explaining $40.86 \%$ of the variance) at the other end of the axis. The vertical axis included status but at a lower level and service to the Federation in a variety of roles.

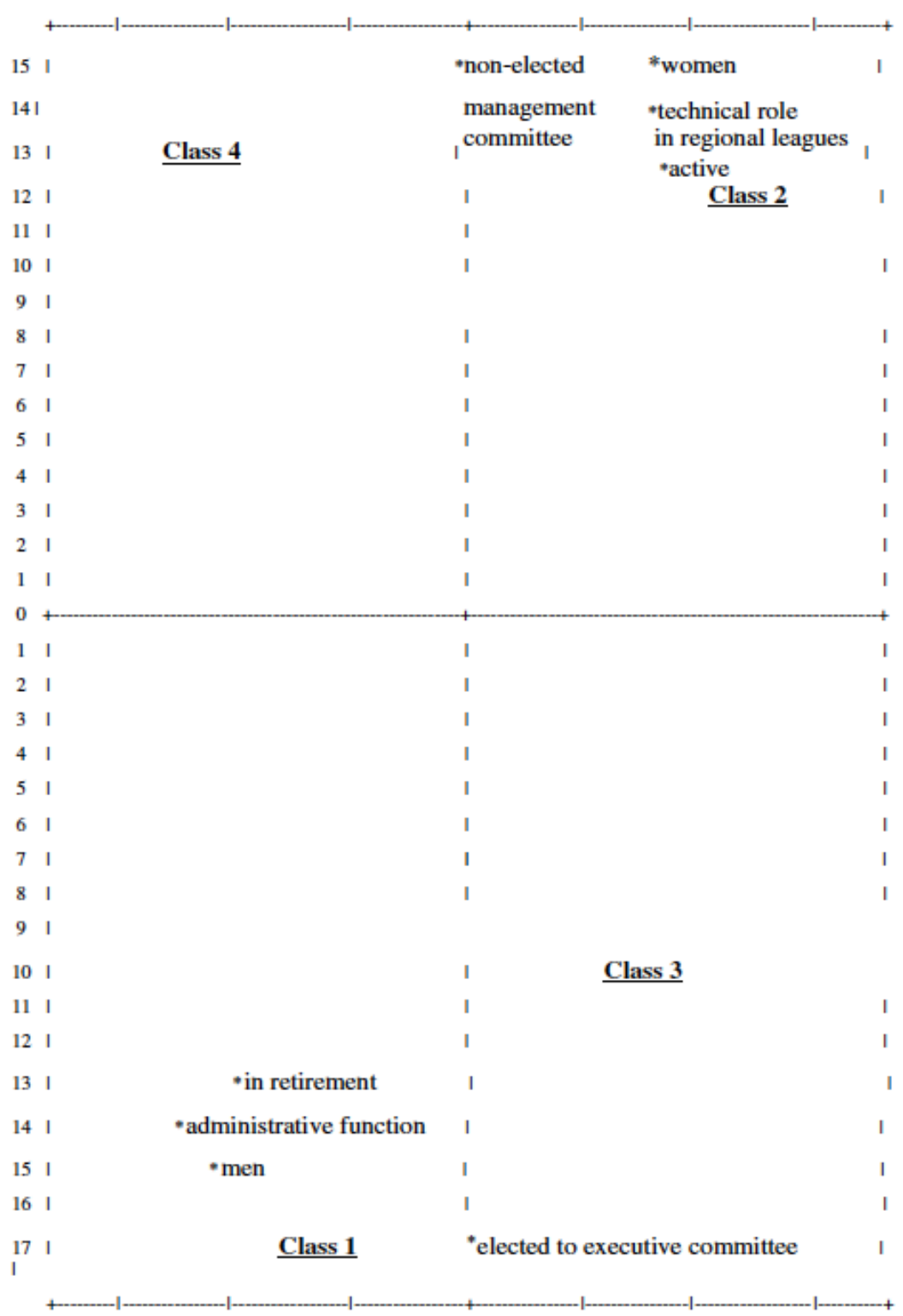

Horizontal axis: First factor: Eigen Value $=.3542$ ( $40.86 \%$ of the inertia explained) Vertical axis: Second factor: Eigen Value $=.3098(35.74 \%$ of the inertia explained $)$

Figure 2. Correspondence analysis mapping lexical classes against key factors. 


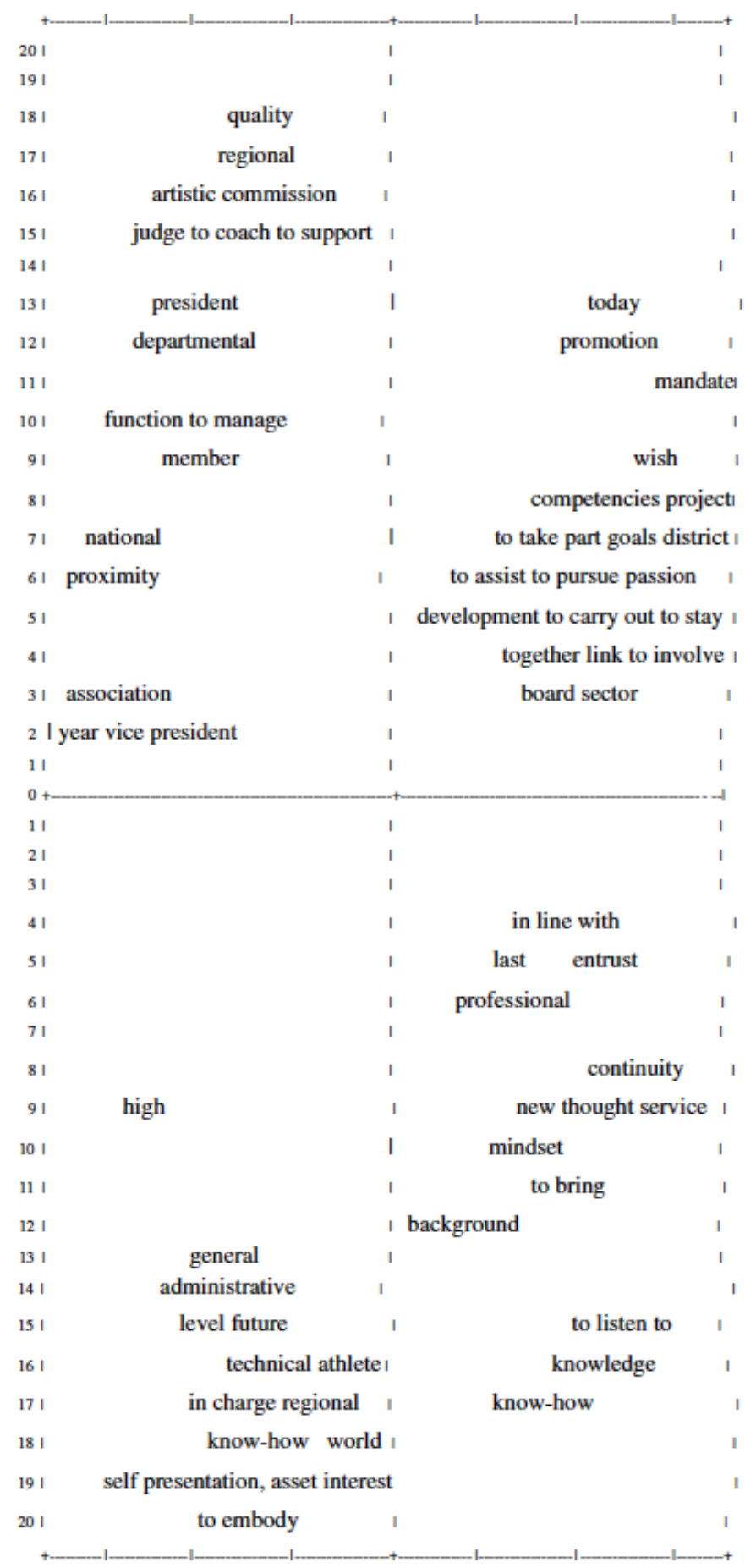

Horizontal axis: First factor: Eigen Value $=.3542(40.86 \%$ of the inertia explained) Vertical axis: Second factor: Eigen Value $=.3098$ ( $35.74 \%$ of the inertia explained)

Figure 3. Distribution of terms used in the two dimensional space.

Notwithstanding the fact that male and female membership of the classes is mixed and that two of the classes (Class 1 and 2) are identified with masculine and feminine approaches, it is noteworthy that the correspondence analysis (see Figure 2) reinforces this claim. There are two clusters identified here, one is males in Class 1, previously elected to the executive, performing and administrative function and in retirement from their paid employment. The second is women in Class 2, previously non-elected, playing active, technical roles, in regional leagues. 
This result seems interesting as it demonstrates that some men are able to enter into senior positions which reflect a feminization of sport management.

This discourse can be congruent with an approach to human resource management in which managers see them as acting in the best interests of the organisation by adopting communication skills (Kerfoot \& Knights, 1998; Knoppers \& Anthonissen, 2008). Wacjman (1998), who studied male and female managers in five multinational companies, found that the emphasis on interaction abilities has meant that male managers have added these skills to their repertoire so that women are not really needed to contribute these skills to organisations. Doherty, Patterson, and Van Bussel (2004) found that volunteer boards often perceived that an expectation to contribute to the committee coincided with an expectation to work together. Moreover, the candidates in Class 2 emphasized passion for their sport. Hatcher (2003) argued that passion has now become a necessary quality that enterprising managers must display. This passion must not be disordered, however, but be controlled. This emphasis on control would allow the use of this discursive practice to be associated with masculinities instead of femininities (Knoppers \& Anthonissen, 2008).

As noted, the candidates of Class 4 engaged in a discourse of service and commitment at a lower level in the organisational hierarchy, placing the emphasis on service to the movement at a grassroots level rather than competences gained. Bernadeau-Moreau (2005) points out that the growing professionalization of French sports organisations reinforces the notion that extensive experience at the grassroots level of federations is no longer regarded as sufficient preparation for work at higher levels of sporting structures. Growing commercialisation and the demands resulting from legislative measures in France mean that there has been progressive distancing of managers in the system from club level sport.

Likewise Vein et al. (1999) have argued that the complexity of managing sport organizations has increased and it is difficult for managers to develop the skills necessary to function within the contemporary sport system. This standpoint is further reflected in the distinction between those with previous experience on the national committee and those without.

A key question in the management literature has been whether some women reject aspects of feminine management styles, adopting attributes which are more typically considered to be those of male managers. This study showed that some women were incorporated in classes which discursively construct a more masculine approach to management or leadership roles. Korabik (1990) suggested that for women, an increased awareness of the androgynous nature of effective leadership behaviours could be a response to the dilemma of their socialisation and managers expected characteristics, and would be a way to surpass the negative effects of sex stereotypes. The results, however, showed that it was these women who have been elected.

\section{Conclusion}

This study represents an exploratory case study investigating how self descriptions may be gendered in the context of candidature for management roles within a NSF. The study adopted an approach advocated in the literature by poststructuralist thought which emphasizes the ongoing social construction of gendered roles. Although other researchers such as Acker (1990), Ely and Meyerson (2000), Meyerson and Kolb (2000), and Rao, Stuart, and Kelleher (1999) have conduct research in this area, the present study extends the understanding of the processes of construction of gendered roles which is essential to the diversity policies. The two stages process is not however a matter of convenience but is under pinned by an essentially different ontological set of assumptions from that which 
informs the dominantly post-structuralist methodologies evident in the literature.

Poststructuralist accounts focus on the social construction of realities though discourse. Our own approach is also constructivist (the fluid nature of identity constructed in the process of self-descriptions by candidates is core to our concerns) but the approach is not just constructivist but is both realist and constructivist (in line with critical realist ontologies: Bhaskar, 2002). Linguistic structures are, we argue, real (and identifiable) as we note in our application of the ALCESTE approach to detect patterns of usage. However, these structures are social constructions, constructed in specific social situations (in this case NSF elections), at particular points in time, to achieve particular outcomes.

Our theoretical position is thus one which seeks to build on both correspondence and coherence criteria of truth (though our goal, as with other forms of discourse analysis is to produce truth-like generalisations rather than universal truths per se). Indeed our account fuses a form of critical discourse analysis with critical realist ontology, an approach recently advocated by one of the leading figures in the development of critical discourse analysis (Fairclough, 2005). The account is critical in the sense of being informed by feminist aspirations to be emancipatory, revealing how linguistic structures embed and reproduce certain gendered outcomes, and by virtue of this knowledge better equip us to challenge such structures and processes. Our approach is thus informed by a network approach to truth. Statements are taken as reflective of a set of external linguistic and other structures. These structures are discursively constructed, but our understanding of the generalisable statements made in relation to these structures and processes can only be developed within a theory- informed explanation of the context. In effect this article is an attempt to tease out the structures, the discursive processes, and the social context in this case while acknowledging that this cannot be undertaken in a value-free manner.

Some limitations do, however, need to be addressed. As Marshall (1993) has pointed out gender equality in terms of representation is not likely to produce significant changes in organizational culture. The new electoral system may perhaps simply constitute a fac, ade allowing the organisation to maintain a clear conscience. Hovden (2000) argued that there was a formidable distance between legislation and realization. Effective management of diversity will require a clear understanding that the benefits of diversity can be derived only through the on-going development of "appropriate managerial skills, attributes and practices" (Chelladurai, 2001, 2006; Cox \& Beale, 1997; Doherty \& Chelladurai, 1999). But this in turn requires a real understanding of how the notion of appropriate skills, attributes and practices is discursively constructed, and of the gendered dimensions of such discursive constructions. The present data provide merely a cross-sectional insight and do not allow any evaluation of the fluidity of the process of identity construction over time. A longitudinal perspective seems necessary to review the implementation of policies promoted in sport organizations if we are to be able to establish the key features that are particularly relevant to the achievement of positive change. Nevertheless the detailed snap shot which this analysis of CSDs provides does generate clear insights into the discursive positioning of candidates at this given point in time.

\section{Note}

1. A doctor; a technical representative by gymnastics discipline (seven), three members elected at the Executive Committee of the International Federation of Gymnastics (FIG) or of the European Union of Gymnastics (UEG); two young persons of less than 26 years and a general technical coordinator. 


\section{References}

Acker, J. (1990). Hierarchies, jobs, bodies: A theory of gendered organisations. Gender and Society, 4,139_158.

Aitchison, C. C. (2000). Poststructural feminist theories of representing others: A response to the 'crisis' in leisure studies' discourse. Leisure Studies, 19, 127_144.

Aitchison, C. C. (2005). Feminist and gender research in sport and leisure management: Understanding the social-cultural nexus of gender-power relations. Journal of Sport Management, 19, 422_441.

Alvesson, M., \& Billing, Y. D. (1997). Understanding gender and organisations. London: Sage.

Benzecri, J. P. (1981). Practice of data analysis. Paris: Dunod.

Bernardeau-Moreau, D. (2005). The professionalization of volunteer leaders in the French Tennis Federation. European Review of Sport Management, 13, 1_15.

Bhaskar, R. (2002). Reflections on meta-reality: Transcendence, emancipation and everyday life. London Sage.

Bontoux, M. (2005). Roles of the leading women in the French gymnastics federation. (Master's thesis University Lyon, 2005).

Book, E. W. (2000). Why the best man for the job is a woman. New York: Harper Collins.

Buzzanell, P. M., \& Liu, M. (2005). Struggling with maternity leave policies and practices: poststructuralist feminist analysis of gendered organizing. Journal of Applied Communication Research, 33, 1_25.

Chantelat, P., Bayle, E., \& Ferrand, C. (2004). Representations of female leaders at work in sport governing bodies: Contextual effect and ambivalences. The International Journal of Sport Science and Physical Education, 66, 143_159.

Chelladurai, P. (2001). Managing organizations for sport and physical activity: A system perspective. Scottsdale, AZ: Holcomb Hathaway Publishers.

Chelladurai, P. (2006). Managing human resources in sport and recreation (2nd ed.). Champaign, IL: Human Kinetics.

Chimot, C. (2004). Gender based distribution of decision making positions in sport organizations. The International Journal of Sport Science and Physical Education, 66, 161_177.

Claringbould, I., \& Knoppers, A. (2007). Finding a 'normal' woman: Selection processes for board membership. Sex Roles, 56, 495_507.

Cockburn, C. (1989). Equal opportunities: The short and long agenda. Industrial Relations Journal, 20, 213_225.

Connell, R. W. (1995). Masculinities. Cambridge: Polity Press.

Cox, T. J., \& Beale, R. L. (1997). Developing competency to manage diversity: Readings, cases and activities. San Francisco: Berrett-Koehler.

DeSensi, J. T., \& Rosenberg, D. (1996). Ethics in Sport Management. Morgantown, WV: Fitness Information Technology.

Doherty, A., \& Carron, A. V. (2003). Cohesion in volunteer sport executive committee. Journal of Sport Management, 17, 116_141. 
Doherty, A., \& Chelladurai, P. (1999). Managing cultural diversity in sport organizations: A theoretical perspective. Journal of Sport Management, 13, 280_297.

Doherty, A., Patterson, M., \& Van Bussel, M. (2004). What do we expect? An examination of perceived committee norms in non-profit sport organisations. Sport Management Review, 7, 109_132.

Eagly, A. H., \& Johannesen-Schmid, M. C. (2001). The leadership styles of women and men. Journal of Social Issues, 57, 781_797.

Ely, R. J., \& Meyerson, D. E. (2000). Theories of gender in organizations: A new approach to organizational analysis and change. Research in Organizational Behaviour, 22, 103_151.

Fairclough, N. (2005). Peripheral vision. Discourse analysis in organization studies: The case for critical realism. Organization Studies, 26, 915_939.

Fink, J. S., Pastore, D. L., \& Riemer, H. A. (2003). Managing employee diversity: Perceived practices and organizational outcomes in NCAA Division 111 athletic departments. Sport Management Review, 6, 147_168.

Fletcher, J. K. (1998). Relational practice: A feminist reconstruction of work. Journal of Management Inquiry, 7, 163_186.

Fondas, N. (1997). Feminization unveiled: Management qualities in contemporary writings. Academy of Management Review, 22, 257_282.

Gatenby, B., \& Hume, K. M. (2004). Powerful discourses for social service_A feminist poststructural and action inquiry. Journal of Organizational Change Management, 17, 269_280.

Hatcher, C. (2003). Refashioning a passionate manager: Gender at work. Gender, Work and Organization, 10, 391_412.

Henry, I., \& Institute of Sport and Leisure Policy. (2007). Transnational and comparative research in sport: Globalisation, governance and sport policy. London: Routledge.

Henry, I., Radzi, W., Rich, E., Shelton, C., Theodoraki, E., \& White, A. (2004). Women, leadership and the Olympic movement. Loughborough: Institute of Sport and Leisure Policy, Loughborough University and the International Olympic Committee.

Hoeber, L. (2004). Putting organizational values into practice: Gender equity for athletes in a Canadian University. (Doctoral dissertation, University of British Columbia, 2004).

Hovden, J. (2000). Gender and leadership selection processes in Norwegian sporting organisations. International Review of Sociology in Sport, 35, 75_82.

Hovden, J. (2005, August). Paradoxes of gender in sport leadership in Norway. Paper presented at the International Association of Physical Education and Sport for Girls and women, Edmonton, Canada.

Jaquette, J. S. (2001). Women and democracy: Regional difference and contrasting views. Journal of Democracy, 12, 111_125.

Jones, A. (1993). Becoming a "girl": Poststructuralist suggestions for educational research. Gender and Education, 5, 157_166.

Kerfoot, D., \& Knights, D. (1998). Managing masculinity in contemporary organizational life: a managerial project. Organization, 5, 7_26.

Knights, D., \& Kerfoot, D. (2004). Between representations and subjectivity: Gender 
binaries and the politics of organizational transformation. Gender, Work and Organization, 11, 430_454.

Knoppers, A., \& Anthonissen, A. (2008). Gendered managerial discourses in sport organizations: Multiplicy and complexity. Sex roles, 58, 93_103.

Kobabik, K. (1990). Androgyny and leadership style. Journal of Business Ethics, 9, 283_292.

Lescure, P. (1999) Synthe `se de la me'thodologie Alceste. Toulouse: Socie'te' Image.

Leveque, S. (2006). Beyond femininity: Usage and non usage of gender in the 2002 Parisian local elections declarations. French Review of Politic Sciences, 55, 501_520.

Lincoln, Y. S., \& Guba, E. G. (1985). Naturalistic inquiry. London: Sage.

Marshall, J. (1993). Organizational cultures and women managers: Exploring the dynamics of resilience. Journal of Applied Psychology, 42, 313_322.

McKay, J. (1997). Managing gender: Affirmative action and organizational power in Australian, Canadian, and New Zealand sport. Albany: University of New York Press.

McKay, J. M., Messner, A., \& Sabo, D. (2000). Masculinities, Gender Relations and Sport (2nd ed.). London: Sage.

McNay, L. (2000). Gender and agency: Reconfiguring the subject in feminist and social theory. Cambridge: Polity Press.

Mennesson, C. (2000). Hard women and soft women: The social construction of identities among female boxers. International Review for the Sociology of Sport, 35, 21_33.

Mennesson, C. (2004). The management of the female practice in male sports: contrasted forms of male domination. The International Journal of Sport Science and Physical Education, 63, 89_106.

Meyerson, D. E., \& Kolb, D. M. (2000). Moving out the 'armchair': Developing a framework to bridge the gap between feminist theory and practice. Organisation, 7, 553_571.

Noel-Jorand, M. C., Reinert, M., Giudicelli, S., \& Dassa, D. (1997). A new approach to discourse analysis in psychiatry, applied to a schizophrenic patient's speech.

Schizophrenia Research, 25, 183_198.

Ozbilgin, M. F. (2000). Is the practice of equal opportunities management keeping pace with theory? Management of sex equality in the financial services sector in Britain and Turkey. Human Resource Development International, 3, 43 _67.

Rao, A., Stuart, R., \& Kelleher, D. (1999). Gender at work: Organizational change for equality. West Hartford, CT: Kumarian.

Reinert, M. (1990). Alceste: A methodology of textual data analysis and an application: Aurelia de G. de Nerval. Bulletin de Me'thodologie Sociologique, 26, 24_54.

Reinert, M. (2002). Alceste, reference manual. France: University St-Quentin en Yvelines.

Schonhardt-Bailey, C. (2005). Measuring Ideas More Effectively: An Analysis of Bush and Kerry National Security Speeches. Political Science \& Politics, 38, 701_711.

Shaw, S., \& Frisby, W. (2006). Can gender equity be more equitable? Promoting an alternative frame for sport management research, education, and practice. Journal of Sport Management, 20, 483_509.

Shaw, S., \& Hoeber, L. (2003). "A strong man is direct and a direct woman is a bitch": 
Gendered discourses and their influence on employment roles in sport organizations. Journal of Sport Management, 17, 347_375.

Shaw, S., \& Penney, D. (2003). Gender equity policies in National Governing Bodies: An oxymoron or a vehicle for change? European Sport Management Quarterly, 3, 78_102.

Shaw, S., \& Slack, T. (2002). It's been like that for Donkey's Years: The construction of gender relations and the cultures of sports organizations. Sport and Society, 5, 86_106.

Tinker, I. (2004). Quotas for women in elected legislatures: Do they really empower women? Women's Studies International Forum, 27, 531_546.

Vein, G., Verhoeven,M., Laporte, W., De Knop, P., Bollaert, L., Taks, M., \& Vincke, J. (1999). In search of macro, meso and micro-sociological antecedents of conflict in voluntary sports federation and clubs with the Flemish situation as a case study. European Journal of Sport Management, 6, 62_77.

Wacjman, J. (1998). Managing like a man: Women and men in corporate management. University Park, PA: Polity Press.

Weedon, C. (1997). Feminist practice and poststructuralist theory. Oxford: Blackwell Publishing.

Wood, L., \& Kroger, R. (2000). Doing discourse analysis: methods for studying action in talk and text. London: Sage.

Yoder, J. D. (2001). Making leadership work more effectively for women. Journal of Social Issues, 57, 815_828. 